\title{
Numerical analysis of heat transfer in air-water heat exchanger with microchannel coil
}

\author{
Vladimir Glazar , Anica Trp, Kristian Lenic, and Fran Torbarina \\ University of Rijeka, Faculty of Engineering, Department of Thermodynamics and Energy Engineering, Vukovarska 58, Rijeka, HR- \\ 51000 , Croatia
}

\begin{abstract}
This paper presents numerical analysis of fluid flow and heat transfer in the heat exchanger with microchannel coil (MCHX). In accordance with previously published experimental results, 3D mathematical model has been defined and appropriate numerical simulation of heat transfer has been performed. Geometry and working parameters of cross-flow air-water heat exchanger with microchannel coil, installed in an open circuit wind tunnel and used in experimental investigations, have been applied in numerical analysis in order to validate the mathematical model. 3D model with air and water fluid flow and heat transfer domains has been used, as it gives more precise results compared to models that assume constant temperatures or constant heat fluxes on the pipe walls. Developed model comprised full length of air and water flows in the heat exchanger. Due to limitations of computational capacity, domain has been divided in multiple computational blocks in the water flow direction and then solved successively using CFD solver Fluent. Good agreement between experimentally measured and numerically calculated results has been obtained. The influence of various working parameters on heat transfer in air-water heat exchanger has been studied numerically, followed with discussion and final conclusions.
\end{abstract}

\section{Introduction}

Numerical analysis is a powerful tool that can be used in different investigations and various fields. When dealing with heat transfer of compact heat exchangers, it gives possibility to test and simulate a number of different designs under numerous operating conditions without need of creation of very expensive real size prototypes. Nevertheless, numerical models without proof of validity can be misleading. Traditional experiments on real size models or on smaller adequate models are performed to improve fundamental understanding of physical behaviour, to improve mathematical models and to estimate validity of model parameters [1].

Compact heat exchangers are widely used for different purposes in industry, transport as well as residential and commercial HVAC systems [2]. Size reduction of compact heat exchangers has led to heat exchangers with flat tubes, commercially known as microchannel coil (further in text: MCHX) [3]. Large number of research papers about MCHX can be found with different topics that deal with both single phase or with phase change processes [4, 5]. Analysis and simulation of heat transfer can be performed experimentally, numerically or by combination of this two main approaches. In paper [6] experimental study of heat transfer characteristics of single-phase turbulent flow of $\mathrm{R}-134 \mathrm{a}$ refrigerant in a rectangular multi-micro channel heat sink has been performed. Main findings of paper demonstrated that well-known correlations for heat transfer could be used to predict heat transfer in multiport microchannel heat sink. Experimental and numerical assessment of the replacement of conventional fin-andtube-condensers by a minichannel heat exchanger in an air/water chiller for residential air conditioning has been analysed in [7]. Authors' main findings were that replacement of a conventional fin-and-tube condenser by a minichannel condenser enables, under almost any operating conditions, reduction of the refrigerant mass with simultaneous increase of efficiency and cooling capacity. Single-phase heat transfer enhancements in microchannel can be also achieved with use of nanofluids. In [8] authors gave review of recent experimental and numerical studies on heat transfer in microchannels using nanofluids. Moreover, authors presented scaling effects, physical properties and main recent applications of nanofluids.

In this paper heat exchanger with microchannel coil has been analysed numerically. In accordance with previously published experimental results [9], 3D mathematical model has been created and appropriate numerical simulation of heat transfer has been performed. Single-phase heat transfer characteristics have been calculated and analysed. Thus, the influence of water inlet velocities and temperatures on heat transfer has been investigated. Geometry and working parameters of crossflow air-water heat exchanger with microchannel coil, installed in an open circuit wind tunnel and used in experimental investigations, have been applied in numerical analysis in order to validate the mathematical 
model. Description of mathematical model and numerical solving, with numerical analysis and final conclusions follows.

\section{Mathematical modelling and numerical solving}

\subsection{Physical model}

Figure 1 shows a schematic diagram of MCHX studied in this paper. MCHX consists of 47 parallel aluminium flat tubes connected with fins. Flat tubes contain 11 small rectangular channels each with hydraulic diameter of 1.44 $\mathrm{mm}$.

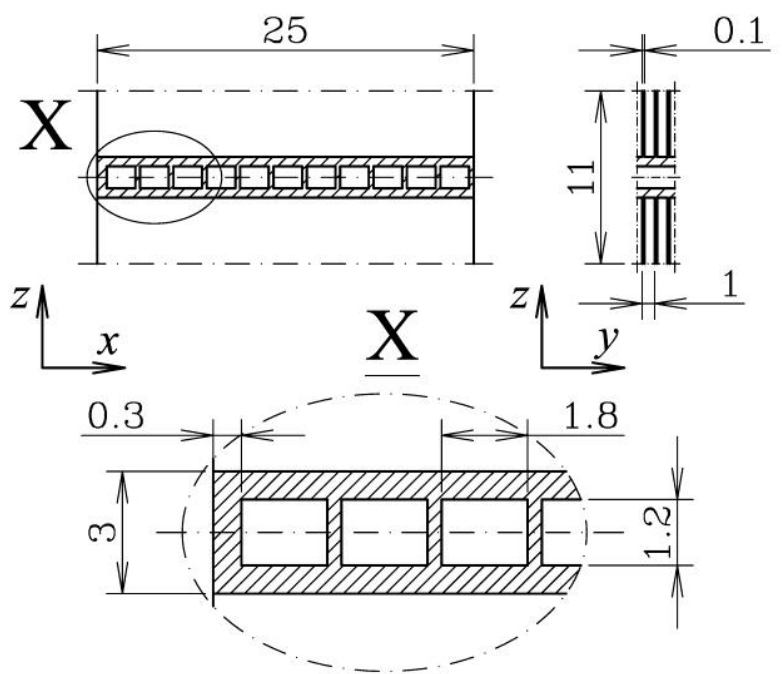

Fig. 1. Schematic diagram of MCHX and basic dimensions (in $\mathrm{mm})$.

The air flow is directed in the direction of $\mathrm{x}$-axis and water flow direction is parallel to the y-axis. Transversal flat tube pitch is in the $\mathrm{z}$-axis direction. Table 1 shows values of basic geometry parameters.

Table 1. Geometry parameters of MCHX

\begin{tabular}{|c|c|}
\hline Geometry parameter & mm \\
\hline Transversal tube row pitch, $P_{\mathrm{t}}$ & 11 \\
\hline Fin pitch, $F_{\mathrm{p}}$ & 1 \\
\hline Fin thickness, $F_{\mathrm{t}}$ & 0.1 \\
\hline Hydraulic diameter, $d_{\mathrm{h}}$ & 1.44 \\
\hline Flat tube dimensions, $l \times w \times h$ & $840 \times 25 \times 3$ \\
\hline
\end{tabular}

Heat transfer and fluid flow numerical simulation of water and air streams has been done. Due to limitations of the computer resources, only part of the heat exchanger, required to describe air and water flow and heat transfer, was taken as computational domain. Two symmetry planes were assumed in the z-direction that divide space between flat tubes in two symmetrical parts. These planes were perpendicular to the fin surface. Additionally, two symmetry planes were assumed in the y-direction on both air, and tube subdomains. A schematic view of the computational domain has been shown in Figure 2. In the figure, the upstream and downstream regions have not been presented in proportional dimensions.

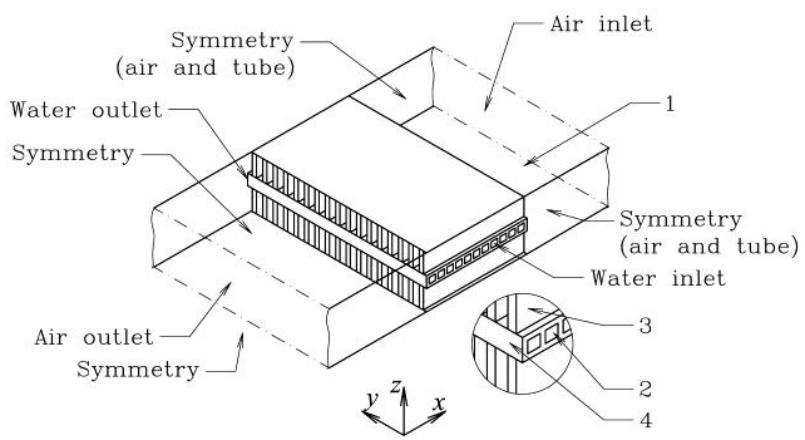

Fig. 2. Schematic view of computational domain.

The computational domain consists of four subdomains: air (1), water (2), fin (3) and flat tubes (4). The total length of the computational domain has been extended 6.5 times from actual internal airspace. The upstream air region has been extended 1.5 times to ensure inlet uniformity. The downstream air region has been extended 5 times, thus a developed flow pattern at the outlet boundary can be assumed.

\subsection{Governing equations}

The governing equations in the Cartesian coordinate system for forced, steady, laminar, three-dimensional, incompressible fluid flow and heat transfer in air, water, fin and tube subdomains are:

\subsubsection{Air and water subdomain}

Continuity:

$$
\operatorname{div}(\rho \overrightarrow{\mathbf{u}})=0
$$

Momentum

$$
\begin{aligned}
& \mathrm{x} \ldots \quad \operatorname{div}(\rho u \overrightarrow{\mathbf{u}})=-\frac{\partial p}{\partial x}+\operatorname{div}(\mu \operatorname{grad} u) \\
& \mathrm{y}_{\ldots} . \quad \operatorname{div}(\rho v \overrightarrow{\mathbf{u}})=-\frac{\partial p}{\partial y}+\operatorname{div}(\mu \operatorname{grad} v) \\
& \text { z... } \quad \operatorname{div}(\rho w \overrightarrow{\mathbf{u}})=-\frac{\partial p}{\partial z}+\operatorname{div}(\mu \operatorname{grad} w)
\end{aligned}
$$

Energy:

$$
\operatorname{div}(\rho \overrightarrow{\mathbf{u}} T)=\operatorname{div}\left(\frac{k}{c} \operatorname{grad} T\right)
$$

In air subdomain, equations (1) to (5) comprise physical properties of air $\left(\rho_{\mathrm{a}}, \mu_{\mathrm{a}}, k_{\mathrm{a}}\right.$ and $\left.c_{\mathrm{p}, \mathrm{a}}\right)$ whilst in 
water subdomain, they comprise physical properties of water $\left(\rho_{\mathrm{w}}, \mu_{\mathrm{w}}, k_{\mathrm{w}}\right.$ and $\left.c_{\mathrm{w}}\right)$.

\subsubsection{Fin and flat tube subdomains}

$$
\operatorname{div}\left(\frac{k}{c} \operatorname{grad} T\right)=0
$$

In fin subdomain, equation (6) comprises physical properties of fin $\left(k_{\mathrm{f}}\right.$ and $\left.c_{\mathrm{f}}\right)$ whilst in flat tube subdomain, it comprises physical properties of flat tube $\left(k_{\mathrm{t}}\right.$ and $\left.c_{\mathrm{t}}\right)$.

\subsection{Boundary conditions}

Boundary conditions are:

the air inlet boundary:

$$
\begin{gathered}
u_{\mathrm{a}}=u_{\mathrm{a}, \text { in }}=\text { const., } v_{\mathrm{a}}=0, w_{\mathrm{a}}=0 \\
T_{\mathrm{a}}=T_{\mathrm{a}, \text { in }}=\text { const. }
\end{gathered}
$$

the water inlet boundary:

$$
\begin{gathered}
u_{\mathrm{w}}=0, v_{\mathrm{w}}=v_{\mathrm{w}, \text { in }}=\text { const., } w_{\mathrm{w}}=0 \\
T_{\mathrm{w}}=T_{\mathrm{w}, \text { in }}=\text { const. }
\end{gathered}
$$

the air outlet boundary:

$$
\frac{\partial u_{\mathrm{a}}}{\partial x}=0, \frac{\partial v_{\mathrm{a}}}{\partial x}=0, \frac{\partial w_{\mathrm{a}}}{\partial x}=0, \frac{\partial T_{\mathrm{a}}}{\partial x}=0
$$

the water outlet boundary:

$$
\frac{\partial u_{\mathrm{w}}}{\partial y}=0, \frac{\partial v_{\mathrm{w}}}{\partial y}=0, \frac{\partial w_{\mathrm{w}}}{\partial y}=0, \frac{\partial T_{\mathrm{w}}}{\partial y}=0
$$

Air symmetry at the left and right boundaries:

$$
\frac{\partial u_{\mathrm{a}}}{\partial y}=0, v_{\mathrm{a}}=0, \frac{\partial w_{\mathrm{a}}}{\partial y}=0, \frac{\partial T_{\mathrm{a}}}{\partial y}=0
$$

Tube symmetry at the left and right boundaries:

$$
\frac{\partial T_{\mathrm{t}}}{\partial y}=0
$$

Air symmetry at the upper and lower boundaries:

$$
\frac{\partial u_{\mathrm{a}}}{\partial z}=0, \frac{\partial v_{\mathrm{a}}}{\partial z}=0, w_{\mathrm{a}}=0, \frac{\partial T_{\mathrm{a}}}{\partial z}=0
$$

Fin symmetry at the upper and lower boundaries:

$$
\frac{\partial T_{\mathrm{f}}}{\partial z}=0
$$

Air - fin, air - tube and water - tube interface respectively: $k_{\mathrm{a}} \frac{\partial T_{\mathrm{a}}}{\partial n}=k_{\mathrm{f}} \frac{\partial T_{\mathrm{f}}}{\partial n}, k_{\mathrm{a}} \frac{\partial T_{\mathrm{a}}}{\partial n}=k_{\mathrm{t}} \frac{\partial T_{\mathrm{t}}}{\partial n}, k_{\mathrm{w}} \frac{\partial T_{\mathrm{w}}}{\partial n}=k_{\mathrm{t}} \frac{\partial T_{\mathrm{t}}}{\partial n}$

\subsection{Numerical solution}

The governing equations and boundary conditions were discretized using the finite volume method, fully described by [10], on a hybrid, non-orthogonal grid. The number of control volumes for MCHX was close to 120 million divided in 28 computational blocks (30 fins in each block for total of 840 fins, 4.180.200 control volumes per computational block). Computational blocks were used due to limitations on the computer resources (available physical memory) that could severely slow down calculation process. The blocks were successively solved in the direction of the water flow. For each following computational block, calculated values (velocities and temperatures) on the water outlet surface of the previous block, have been set up as the water inlet conditions of the next block. Figure 3 gives a detail of grid system for regions of air, water and flat tube.

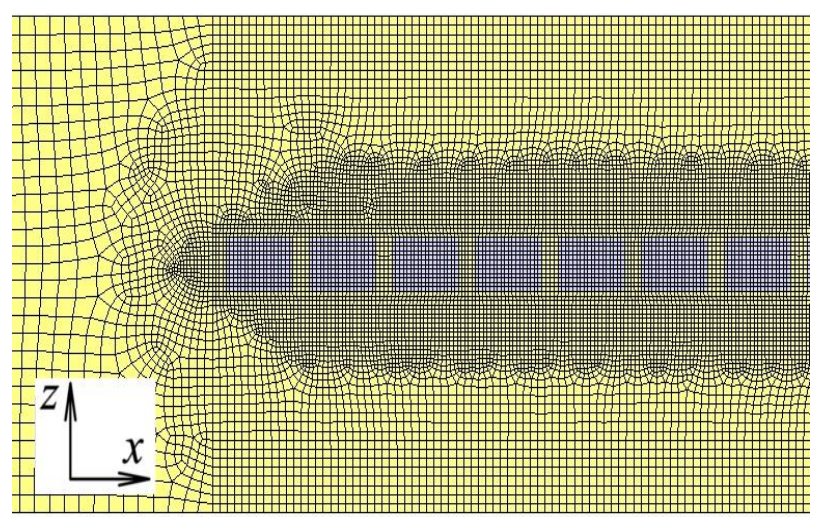

Fig. 3. Detail of the grid system: front view.

Described successive block calculation procedure saves some computational time and excludes need for supercomputing on hardware with large amount of physical memory. Detailed explanation of the procedure is given in [11].

Convergence criteria for momentum ( $\mathrm{x}, \mathrm{y}, \mathrm{z}$-velocity) and energy was set to $10^{-5}$ and for continuity to $10^{-3}$. Time needed to reach convergence criteria for all 28 computational blocks of one setup was approximately 24 hours.

Heat transfer and fluid flow simulations were performed using fluid flow and heat transfer solver FLUENT. All water velocity vectors and temperatures between computational blocks were linked with internal scripting language included in CFD software. Fluids were assumed to be incompressible with constant physical property values and the flows were assumed to be laminar. The SIMPLE algorithm for pressure-velocity coupling was used to ensure mass conservation and to obtain a pressure field. The convection-diffusion terms have been discretized using the Upwind scheme. 


\section{Validation}

Comparison of experimental and numerical data has been done in order to validate used air/water numerical simulation. Comparison has been accomplished for same ranges of air and water inlet temperatures and velocities used in previous experimental investigations. In accordance with the heat exchanger used for the experiments, numerical 3D model of adequate geometry was developed.

\subsection{Experimental setup and procedure}

In an open circuit wind tunnel, the measurements of working fluid temperatures, mass flow rates and pressure drops for heat exchanger with microchannel coil have been performed. Figure 4 shows schematic view of experimental facility (wind tunnel).

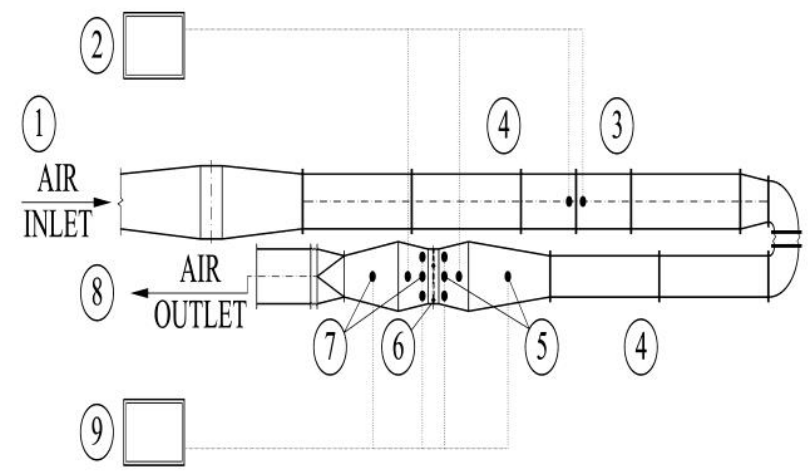

LEGEND: 1. air inlet (from air handling unit), 2. data acquisition system for pressure drops, 3. orifice, 4 . air settling ducts, 5 . air inlet temperature and air inlet velocity sensors, 6. MCHX (with installed water temperature in/out sensors), 7. air outlet temperature and velocity sensors, 8. air outlet, 9. data acquisition system for velocities and temperatures

Fig. 4. Schematic view of experimental facility (wind tunnel).

The main components of the system were air supply unit with centrifugal fan, measuring orifice, heat exchanger with microchannel coil, instrumentations and data acquisition systems. The open circuit wind tunnel system, containing air-handling unit with heating and cooling section, was used to draw air over the tested heat exchanger. The National Instruments SCXI data acquisition, automation and control module system was used and all virtual instruments were developed in LabVIEW. Details about measurement procedures, setups and equipment have been given in [9].

Figure 5 shows positioning of thermocouple sensors set for temperature measurements of air leaving heat exchanger relative to computational domain. Thermocouple field placed upstream of MCHX was composed of three and thermocouple field placed downstream of MCHX was composed of twelve $K$ type thermocouples. Four of them were used for comparison between experimental and numerical data.

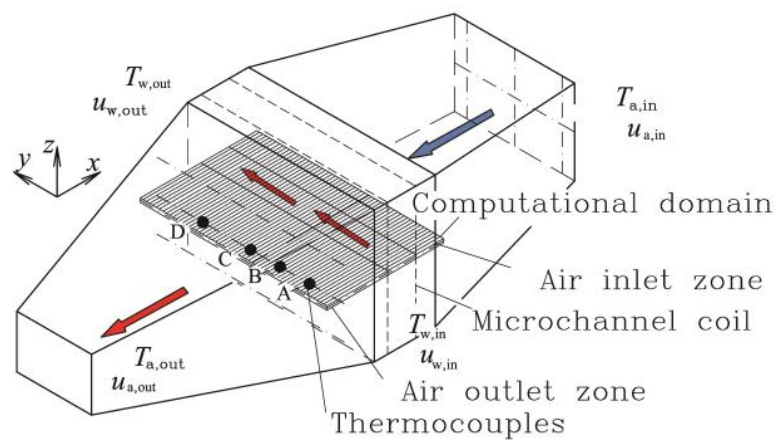

Fig. 5. Positioning of thermocouples and computational domain.

Thermocouple fields were placed $50 \mathrm{~mm}$ before and after MCHX (in X-direction). Thermocouple row used for comparison of numerical and experimental results was placed in symmetry line of air flow and parallel with water flow. Thermocouple displacements in y-direction from water inlet surface are given in Table 2.

Table 2. Thermocouples distance from water inlet (y-direction).

\begin{tabular}{|c|c|c|c|}
\hline $\begin{array}{c}\text { Thermo- } \\
\text { couple }\end{array}$ & $\begin{array}{c}\text { Distance in } \\
\text { y-direction, mm }\end{array}$ & $\begin{array}{c}\text { Thermo- } \\
\text { couple }\end{array}$ & $\begin{array}{c}\text { Distance in } \\
\text { y-direction, } \mathbf{~ m m}\end{array}$ \\
\hline A & 150 & C & 430 \\
\hline B & 300 & $\mathrm{D}$ & 645 \\
\hline
\end{tabular}

Temperatures for each point, $T_{\mathrm{a}, \text { out }}$, used in later comparison have been calculated as average values of all measured air outlet temperatures during obtained steady state [9].

\subsection{Comparison between experimental and numerical results}

Series of numerical calculations, with air and water inlet temperatures and velocities used in experimental investigation, have been done in order to validate mathematical model and numerical procedure. Working parameter setup with following values has been used: the range of water inlet velocities was from 0.03 to $0.11 \mathrm{~m} \mathrm{~s}^{-1}$, air inlet temperature was $295.15 \mathrm{~K}$, air inlet velocity was $1.58 \mathrm{~m} \mathrm{~s}^{-1}$ and water inlet temperature was $308.15 \mathrm{~K}$. Results of comparison have been shown on Figure 6.

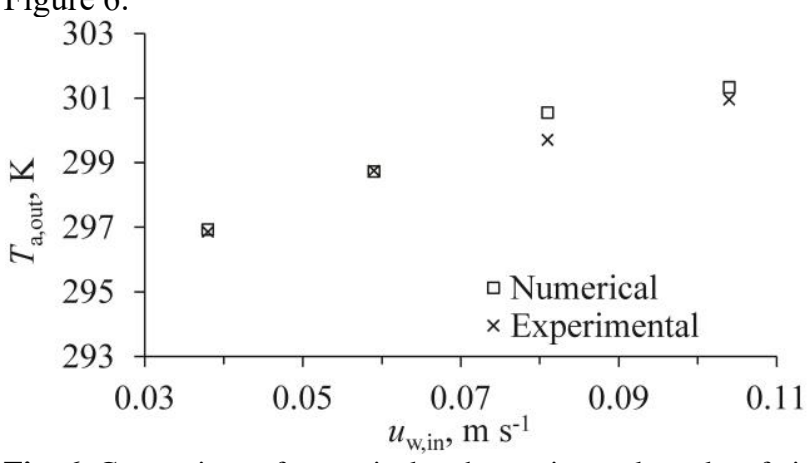

Fig. 6. Comparison of numerical and experimental results of air outlet temperature for different water inlet velocities. Test conditions: $T_{\mathrm{a}, \mathrm{in}}=295.15 \mathrm{~K}, T_{\mathrm{w}, \mathrm{in}}=308.15 \mathrm{~K}, u_{\mathrm{a}, \mathrm{in}}=1.58 \mathrm{~m} \mathrm{~s}^{-1}$.

Numerically obtained results were given for computational block number 15 , which matches to the position of thermocouple $\mathrm{C}$ shown on Figure 5. It can be 
seen that calculated air outlet temperatures coincide well with measured ones, especially at lower water inlet velocities where differences are smaller than $\pm 0.1 \mathrm{~K}$. In case of higher water inlet velocities, differences are in range of $\pm 0.5 \mathrm{~K}$. Figure 7 gives insight in numerically obtained air outlet temperatures along water flow direction (y-direction).

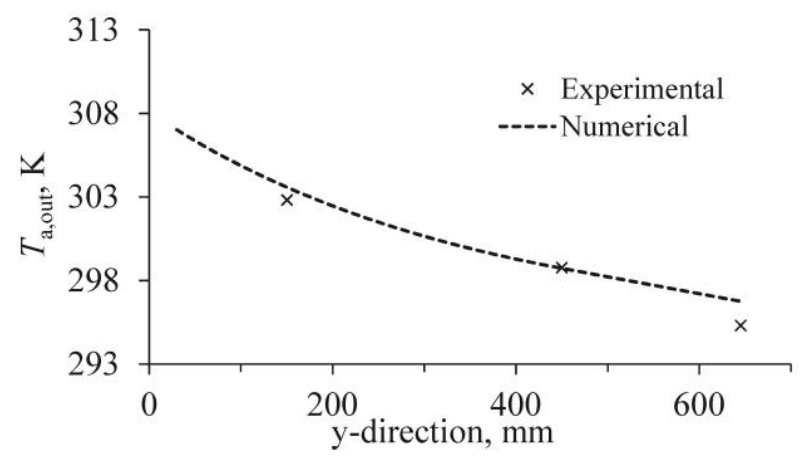

Fig. 7. Numerically obtained distribution of air outlet temperatures along water flow direction (y-direction) compared to experimental results. Test conditions: $T_{\mathrm{a}, \text { in }}=295.15 \mathrm{~K}, T_{\mathrm{w}, \text { in }}=$ $308.15 \mathrm{~K}, u_{\mathrm{a}, \text { in }}=1.58 \mathrm{~m} \mathrm{~s}^{-1}, u_{\mathrm{w}, \text { in }}=0.059 \mathrm{~m} \mathrm{~s}^{-1}$.

Temperature differences between measured and numerical data for analysed points varies from $\pm 0.1 \mathrm{~K}$ to $\pm 0.7 \mathrm{~K}$

It can be seen that numerical simulation results coincide well with the experimental data and that deviations are within an acceptable range. Temperature differences are smaller than $\pm 0.7 \mathrm{~K}$ for all measuring points, what can be taken as assertion of used numerical simulation validity. Therefore, it can be concluded that described mathematical model and numerical calculations can be used for analysis of heat transfer in cross-flow airwater heat exchanger with microchannel coil.

\section{Numerical results}

After validation of the numerical model, a set of 35 different working parameter setups has been applied to the mathematical model of MCHX and solved numerically. Geometry parameters were equal in all numerical calculations and following working parameters were constant: air inlet temperature $295.15 \mathrm{~K}$ and air inlet velocity $1.58 \mathrm{~m} \mathrm{~s}^{-1}$. Numerical calculations were performed for water inlet temperatures ranging from 303.15 to $323.15 \mathrm{~K}$ and for different water inlet velocities ranging from 0.03 to $0.11 \mathrm{~m} \mathrm{~s}^{-1}$. Grid sizes were equal to the grid sizes used in the validation analysis described before. The total length of numerically analysed heat exchanger was $450 \mathrm{~mm}$. Computational time to reach adequate convergence rate for each computational block was 50 minutes on standard multiple core processors (I7 $7^{\text {th }}$ generation). Total time for one working parameter setup run parallel on four cores was between 15 and 20 hours. Some of the results are illustrated further in this paper.

\subsection{Velocity vectors and temperature fields}

Numerical simulation results of air velocity vectors are presented on Figure $8 \mathrm{a}$ and appropriate pathlines of velocity magnitudes are shown on Figure $8 \mathrm{~b}$

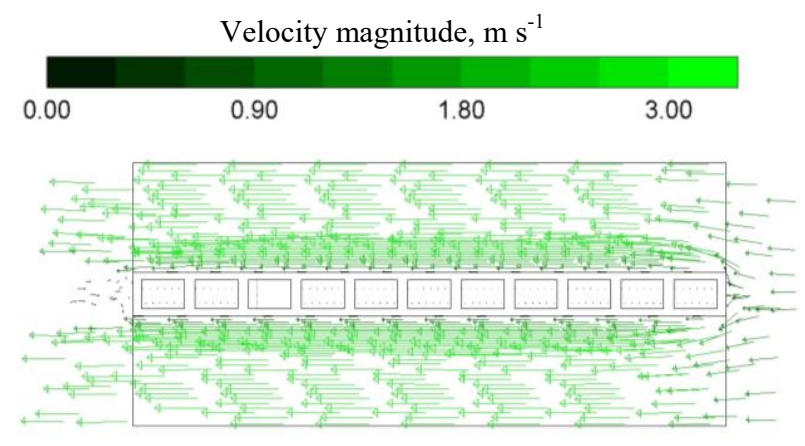

(a)

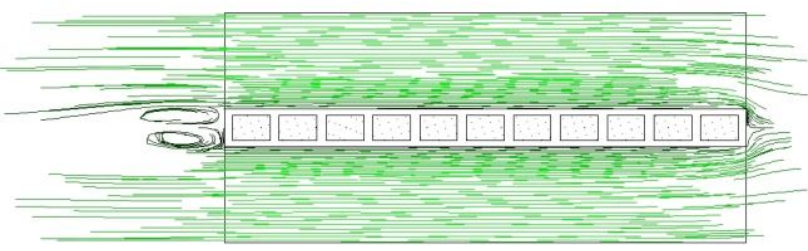

(b)

Fig. 8. Air velocity vectors in symmetry plane (y-direction) of computational block 1 (a) and pathlines of velocity magnitudes for same surface (b). Test conditions: $T_{\mathrm{a}, \mathrm{in}}=295.15 \mathrm{~K}, T_{\mathrm{w}, \mathrm{in}}=$ $308.15 \mathrm{~K}, u_{\mathrm{a}, \text { in }}=1.58 \mathrm{~m} \mathrm{~s}^{-1}, u_{\mathrm{w}, \text { in }}=0.059 \mathrm{~m} \mathrm{~s}^{-1}$.

The maximal velocity values occur near air space and fins symmetry plane. Lowest velocities are in space behind flat tubes where small swirls can be seen.

Figure 9 shows temperature fields for different water inlet temperatures in $\mathrm{X}-\mathrm{Z}$ plane.

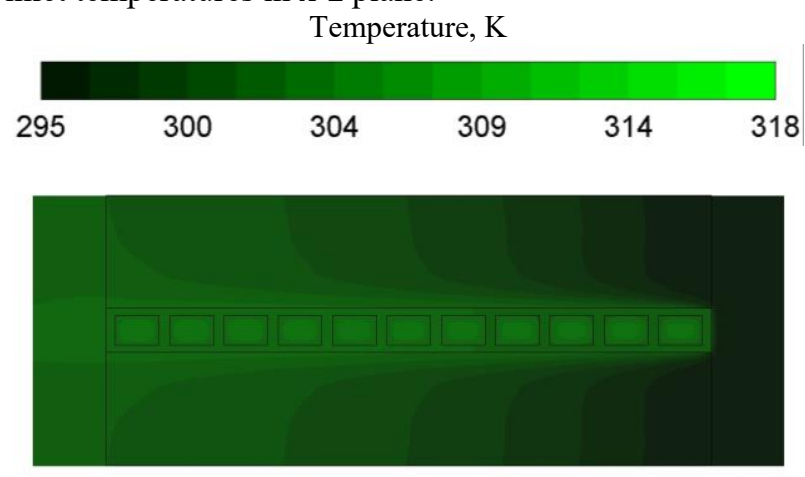

(a)

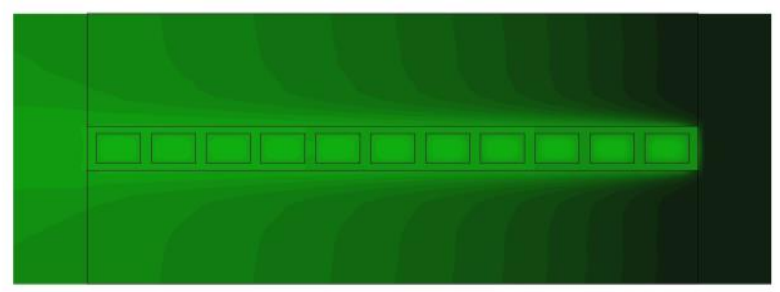

(b)

Fig. 9. Temperature fields in symmetry line (y-direction) of computational block 1 for $T_{\mathrm{w}, \text { in }}=308.15 \mathrm{~K}$ (a) and $T_{\mathrm{w}, \text { in }}=$ $318.15 \mathrm{~K}$ (b). Test conditions: $T_{\mathrm{a}, \mathrm{in}}=295.15 \mathrm{~K}, u_{\mathrm{a}, \text { in }}=1.58$ $\mathrm{m} \mathrm{s}^{-1}, u_{\mathrm{w}, \mathrm{in}}=0.059 \mathrm{~m} \mathrm{~s}^{-1}$. 
The obtained temperature fields show dependence of the temperature distributions on water inlet temperature. In regions with higher local air velocities (boundary layer near flat tube), there is higher air temperature gradient perpendicular to airflow. Temperature field section (in the $y-z$ plane) through small channel number 1 is shown on Figure 10a and through small channel number 11 in Figure 10b.
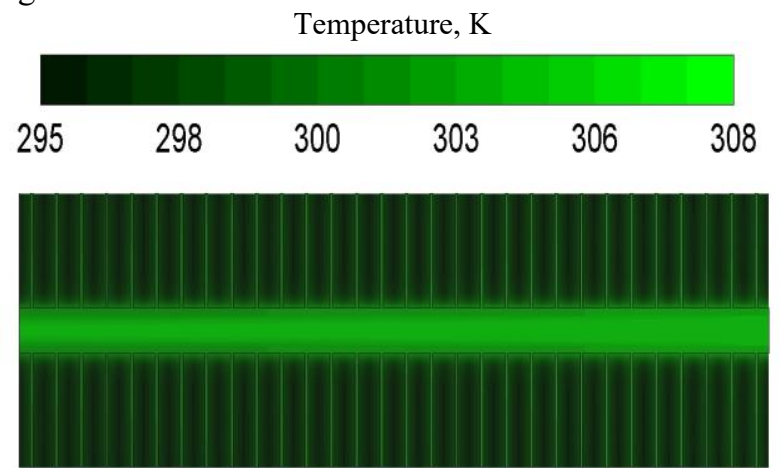

(a)

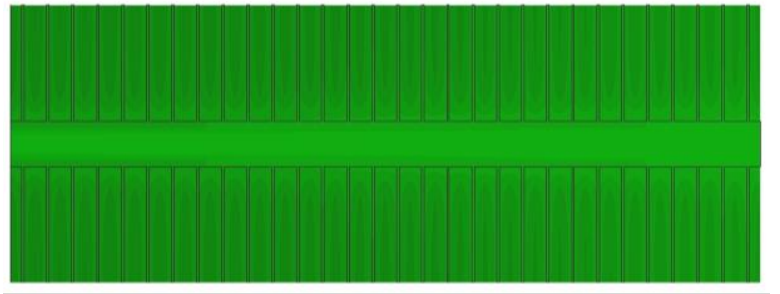

(b)

Fig. 10. Temperature fields in $y-z$ cross sections of computational block 1 through flat tube small channel number 1 (a) and small channel number 11 (b). Test conditions: $T_{\mathrm{a}, \mathrm{in}}=$ $295.15 \mathrm{~K}, u_{\mathrm{a}, \text { in }}=1.58 \mathrm{~m} \mathrm{~s}^{-1}, T_{\mathrm{w}, \text { in }}=308.15 \mathrm{~K}, u_{\mathrm{w}, \text { in }}=0.059 \mathrm{~m} \mathrm{~s}^{-1}$.

While water temperature in small channels decreases, air temperature rises in the direction of airflow from first (Figure 10a) to last small channel (Figure 10b). In crosssection created through small channel number 1 (Figure 10a) air temperature is still low with values close to air inlet temperatures. Passing between fins, air heats up and in cross-section region through small channel 11 gets highest temperature values. Temperature fields for crossflow heat exchanger, both for the cross-section planes in directions of air ( $x-z$ plane) and water ( $y-z$ plane) flows can be seen on Figure 11 in isometric view. Temperature, $\mathrm{K}$

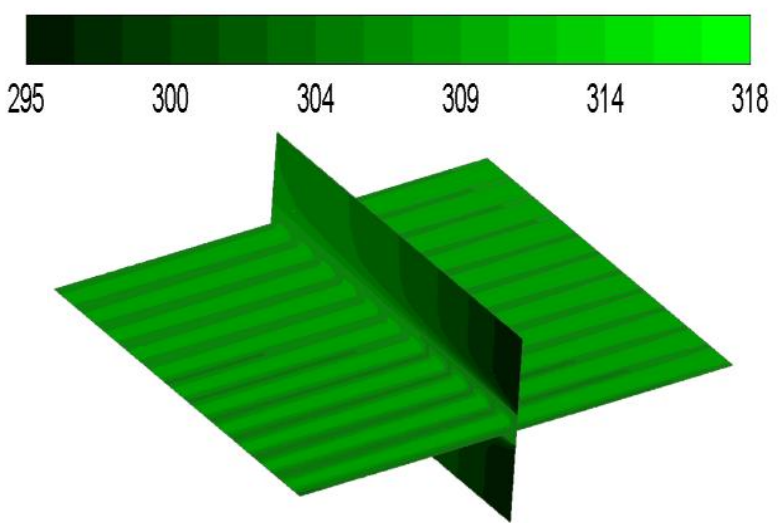

(a)

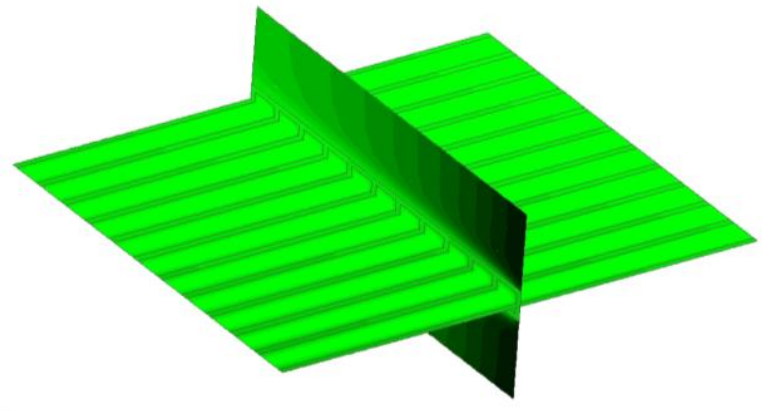

(b)

Fig. 11. Iso view of computational block 1 temperature fields through flat tubes symmetry lines for $T_{\mathrm{w}, \text { in }}=308.15 \mathrm{~K}$ (a) and $T_{\mathrm{w}, \text { in }}=318.15 \mathrm{~K}$ (b). Test conditions: $T_{\mathrm{a}, \text { in }}=295.15 \mathrm{~K}, u_{\mathrm{a}, \text { in }}=$ $1.58 \mathrm{~m} \mathrm{~s}^{-1}, u_{\mathrm{w}, \mathrm{in}}=0.059 \mathrm{~m} \mathrm{~s}^{-1}$.

\subsection{Distribution of air and water temperatures}

From previous analysis of heat transfer in MCHX it can be noticed that heat transfer is greatly influenced by flow conditions in the boundary layer near the flat tube and fin surfaces. Airflow conditions between fins and tubes depend on air inlet velocities. Water (Figure 12a) and air outlet (Figure 12b) temperature distributions along water flow direction for different water inlet velocities are given.

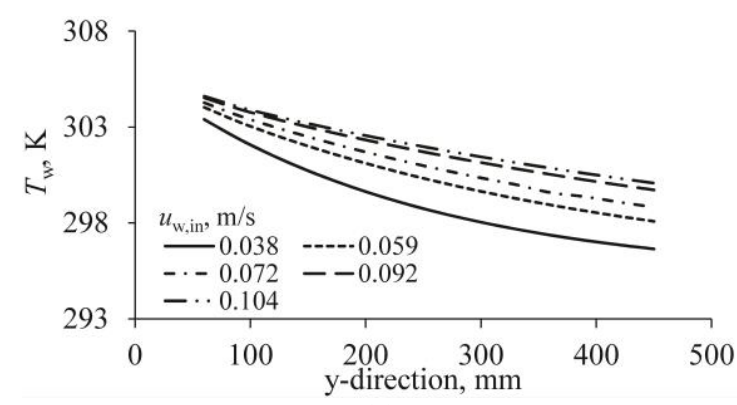

(a)

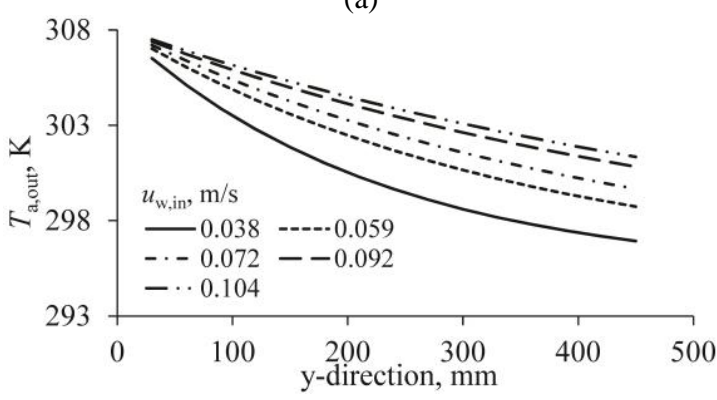

(b)

Fig. 12. Numerically obtained distribution of water (a) and air outlet (b) temperatures along water flow direction (y-direction) for different water inlet velocities. Test conditions: $T_{\mathrm{a}, \text { in }}=$ $295.15 \mathrm{~K}, u_{\mathrm{a}, \text { in }}=1.58 \mathrm{~m} \mathrm{~s}^{-1}, T_{\mathrm{w}, \text { in }}=308.15 \mathrm{~K}$.

In water inlet region, differences of air outlet temperatures for different water inlet velocities are smaller compared to zones further in water flow direction (y-direction). The same is valid also for water temperatures. Higher water inlet velocity gives higher temperatures of heated air. Distributions of numerically obtained air outlet and water temperatures in water flow direction for different water inlet temperatures are given on Figure 13. 


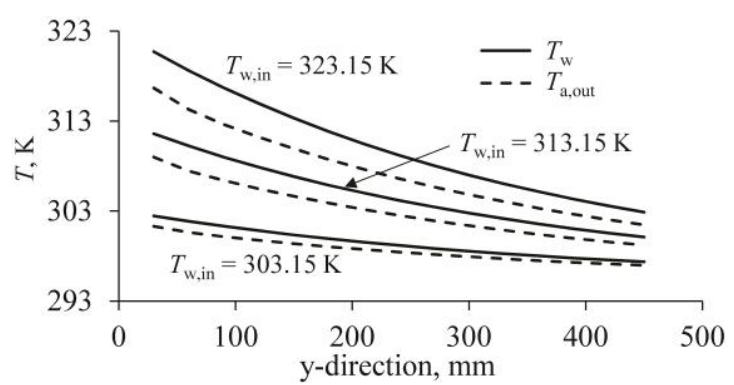

Fig. 13. Numerically obtained distributions of air outlet and water temperatures along water flow direction (y-direction) for different water inlet temperatures. Test conditions: $T_{\mathrm{a}, \mathrm{in}}=$ $295.15 \mathrm{~K}, u_{\mathrm{a}, \text { in }}=1.58 \mathrm{~m} \mathrm{~s}^{-1}, u_{\mathrm{w} \text {,in }}=0.059 \mathrm{~m} \mathrm{~s}^{-1}$.

Air and water temperature differences are higher in case of higher inlet water temperatures. In water flow direction both temperatures of air and water decreases.

\section{Conclusion}

Heat transfer in the heat exchanger with microchannel coil has been numerically analysed in this paper. In accordance with previously published experimental results, 3D mathematical model has been created and appropriate numerical simulation of air and water fluid flow and heat transfer has been performed. Good agreement between experimentally measured and numerically calculated data has been obtained. Numerical simulations were performed in the following range of water velocities and temperatures: water inlet velocities were in a range from 0.03 to $0.11 \mathrm{~m} \mathrm{~s}^{-1}$, and water inlet temperatures were in range from 303.15 to $323.15 \mathrm{~K}$. A set of 35 different working parameter setups has been applied to the mathematical model of cross-flow MCHX and solved numerically. Appropriate dependences of air and water temperatures on water inlet velocities and temperatures have been shown.

Main aim of this paper was to make numerical analysis of heat transfer in the heat exchanger with microchannel coil in an air-water heat exchange application. Validated and verified numerical model could be used for optimization of geometry parameters of the heat exchanger with microchannel coil.

This work has been fully supported by Croatian Science Foundation under the project HEXENER (IP-2016-06-4095).

\section{Nomenclature}

$\begin{array}{ll}\mathrm{c} & \text { specific heat capacity, } \mathrm{J} \mathrm{kg}^{-1} \mathrm{~K}^{-1} \\ d_{\mathrm{h}} & \text { hydraulic diameter, } \mathrm{m} \\ F_{\mathrm{p}}, F_{\mathrm{t}} & \text { fin pitch, fin thickness, } \mathrm{m} \\ k & \text { thermal conductivity, } \mathrm{W} \mathrm{m}^{-1} \mathrm{~K}^{-1} \\ n & \text { normal direction coordinate, } \mathrm{m} \\ p & \text { pressure, } \mathrm{Pa} \\ P_{\mathrm{t}} & \text { transversal } \mathrm{MCHX} \text { tube row pitch, } \mathrm{m} \\ T & \text { temperature, } \mathrm{K} \\ u, v, w & \text { velocity components, } \mathrm{m} \mathrm{s}^{-1} \\ \overrightarrow{\boldsymbol{u}} & \text { velocity vector, } \mathrm{m} \mathrm{s}^{-1} \\ \mathrm{x}, \mathrm{y}, \mathrm{z} & \text { Cartesian coordinates, } \mathrm{m}\end{array}$

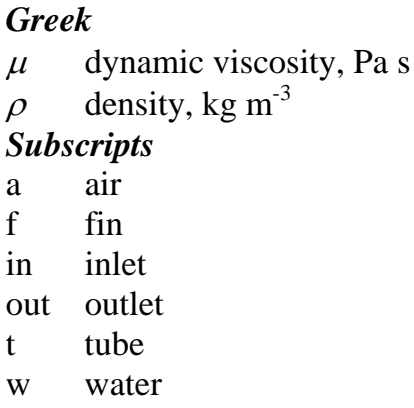

\section{References}

1. B. H. Thacker, S. W. Doebling, F. M. Hemez, M. C. Anderson, J. E. Pepin, E. A. Rodriguez, Concepts of Model Verification and Validation (NNSA \& DOE, Los Alamos, 2004.)

2. T. Kuppan, Heat Exchanger Design Handbook (CRC Press, 2013.)

3. S. Kandlikar, S. Garimella, D. Li, S. Colin, M. R. King, Heat Transfer and Fluid Flow in Minichannels and Microchannels (Butterworth-Heinmann, United States of America, 2016.)

4. M. Asadi, G. Xie, B. Sunden, A review of heat transfer and pressure drop characteristics of single and two-phase microchannels, Heat Mass Transfer. 79, 34-53 (2014)

5. N. A. A. Qasem, S. M. Zubair, Compact and microchannel heat exchangers: A comprehensive review of air-side friction factor and heat transfer correlations, Energ. Convers. Manage. 173 (1), 555601 (2018)

6. A. S. Dalkilic, O. Mahian, S. Yilimaz, K. Sakamatapan, S. Wongwises, S., Experimental investigation of single-phase turbulent flow of $R$ $134 a$ in a multiport microchannel heat sink. Heat Mass Transfer. 89, 47-56 (2017)

7. F. I. Gomez, J. R. G. Cascales, F. H. Mompean, A. L. Belchí, Experimental assessment of the replacement of a conventional fin-and-tube condenser by a minichannel heat exchanger in an air/water chiller for residential air conditioning, Energ. Buildings. 144 (1), 104-116 (2017)

8. A. A. Hussiena, M. Z. Abdullah, M. A. Al-Nimr, Single-phase heat transfer enhancement in micro/minichannels using nanofluids: Theory and applications, Appl. Energ. 164 (15), 733-755 (2016).

9. V. Glazar, A. Trp, K. Lenic, M. Kirincic, Experimental Analysis of Air-Water Heat Exchanger with Microchannel Coil Exposed to Different Working Parameters (EuroSun 2018, 2018.)

10. H. K. Versteeg, W. Malalasekera, An Introduction to Computational Fluid Dynamics: The Finite Volume Method (Pearson, Prentice hall, 2007.)

11. V. Glazar, B. Frankovic, A. Trp, Experimental and numerical study of the compact heat exchanger with different microchannel shapes. Int. J. Refrig. 51 (1), 144-153 (2015) 